\title{
Development and Validation of Extracurricular
}

\section{Instructional Package (EIP) in Social Studies}

\author{
Dr. (MRS) Okoro, C.O. \\ University of Port Harcourt, Port Harcourt (Rivers State) \\ Nigeria
}

\author{
Accepted: May 09, 2013 Published: June 14, 2013 \\ Doi:10.5296/ijld.v3i3.3863 URL: http://dx.doi.org/10.5296/ijld.v3i3.3863
}

\begin{abstract}
The purpose of this study is to develop extracurricular activities for social studies instruction and to compare learning outcomes in the extracurricular activities and the conventional groups. To achieve these objectives two research questions and three hypotheses were formulated. Four instruments were developed. The validated extracurricular instructional package((EIP) was presented to the experimental group while the control group was taught the same social studies topics using the conventional approach. the major findings were that (1) JS 1 Students taught with extracurricular instructional packages relationship develop more cooperative attitude to work (2) exhibited cordial relationship with others (3) developed positive attitude to work. Recommendations were made: Teachers work load should be restructured to accommodate their involvement in extracurricular programs (2) More flexible time-release from teaching or in structuring the allow time for activities during school day etc.
\end{abstract}

\section{INTRODUCTION}

Social studies has been defined variously by many authorities: some regard it as a synonyms for citizenship education which aims to train individual to live co-operatively with one another, to appreciate cultures, cultures other than one's culture and to share with one another (Dike, 2002). Social studies, according to Adeyemi (2004) centers around man, that is on how man manipulates and is manipulated by the various environments in which he finds himself. All these connotes that social studies is concerned with the political, geographical, scientific and technical environments to confront the challenges of survival on the earth as his home. Nzeribe (2002) opines that social studies is an investigation of human activity which studies man at home, at work, in politics, at play, in the community, nation and in every programme of his life. It is an embracing subject as it stresses the relationship between all aspects of life and learning, incorporating the knowledge of the individual subjects in the discussion of all aspects of man and his environment. The fact about social studies is that it draws its character from social sciences, natural sciences and humanities to constitute its autonomy and identity.

In Nigeria, the introduction of social studies into the curricular is seen as a way by which national consciousness, unity in diversity, national tolerance and respect for others are to be taught. The initial objective of social studies in Nigeria relates to the relationship of subjects and the broadening of the country's education system.

This is to say that social studies could be the answer to Nigeria's problems. Ibikunle, (2001) asserts that the new integrated social studies direct the attention of Nigerian children into their own immediate environment before it attempts to show them more of the other world. This promotes a greater integration of learning experience as it employs systematic coorelation 
of subjects around themes drawn from the functions of living. It is also organized around problem-solving.

To ensure that learners are exposed to learning experiences which will shape their behaviors, foster values, ideals, solve social/personal problems in the society, the curriculum must be planned and developed to diagnose the needs of society and learners. Curriculum specialists and educators view curriculum as a way of gaining experimental and problem solving approaches. These experiences are acquired through three major curriculum categories namely programme of studies, programme of activities, and programme of guidance. These programmes represent a mirror image of a nation's state of development (Dike 1995). Curriculum therefore should be seen as an avenue through which a society provides solutions to her identified problems and since the problems of a society vary with time, its curricular should also be adaptive. Ituen (1995) in highlighting the need for schools to give adequate attention to these categories of curriculum in distinguishing these components, noted that programme of studies comprises subjects studied in schools, in order to cultivate the intellect and to disciple the mind. Programme of guidance is an organized effort on the part of the school to help students to understand themselves and identify their academic difficulties with a view to finding suitable solutions to them, while programme of activities are all school sponsored learning activities. these components have complementary functions in achieving educational goals.

As demand for life-long education increases a variety of factors in Nigeria such as political instability, economic recession, struggle for national integration amidst divergent ethnicities, increasing crime rate etc, raise serious doubts towards the ability of the conventional curriculum to solve the challenges of the present time. because of the criticisms leveled against the conventional curriculum, Ukah (2003) advocates for the reversal of the conventional curriculum to a curriculum of "self integration" designed to enable citizens to see how "culture shapes their lives and how then can shape reality" The National Policy On education (2004) therefore places a great emphasis on the acquisition of practical and applied skills, which are necessary to attain self-reliance, as a result, curriculum specialists have introduced changes in curriculum design.

Some of these curriculum innovations are: Contextual learning where students employ their academic understandings and abilities in a variety of in and out-of-school context to solve real-world problems. Problem-based learning-solution of a real world problem shaping the whole learning experience of the students, and Metacognition - thinking about thinking "assisting learners to know what they know and what they don't know" extracurricular Activities which means all the school based or school sponsored activities and events presented under the auspices of a school.

The objectives of these curriculum innovations are:-

Development of skill in social living, development of ethnical value and education for self integration and liberation.

The study therefore is an attempt to contribute to curriculum development in Nigeria through validation of extracurricular instructional packages and events presented under the auspices of a school, which enhance its overall academic programs. Norwood Board of Education (USA) highlighted the importance of the extracurricular activities as follows.

1. Develop useful new capabilities in learners that can lead to the extension of career opportunities.

2. Develop pupil initiative and provide for the exercise of responsibility

3. Development leadership capabilities and good organizational skills.

4. Aid learners in social skills 
5. Enable learners to explore a wide range of individual interest that might not be available in the regular program. Schools and employers of labor are beginning to care about the extracurricular activities students were involved

\section{STATEMENT OF PROBLEM}

Social studies were established in Nigeria because of its unique role in giving young Nigerians a firm base in national unity. It was expected that through social studies Nigerian would.

- Develop a sympathetic appreciation of the diversity and interdependence of all members of the local community, national and international communities

- $\quad$ Ensure the acquisition of relevant knowledge, skills and attitudes which are essential pre-requisite to personal development as well as to a positive personal contribution to betterment of mankind.

- Develop respect and tolerance of the opinions of others in disagreement and willingness to accept necessary changes in system of law and order.

Decades after its implementation Nigerian is skill besieged by many national problems such as youth restiveness, drug abuse, cultism, ethnicity, students graduate without acquiring leadership skills? part of problem may be because social studies curriculum had placed more emphasis on knowledge acquisition with the exclusion of opportunities to assist students to develop morally and socially. Extracurricular activities have the potentials to assist the learners to overcome intolerance in small and large communities, foster a more cooperative environment, encourage complex building and reduce school dropout. This study wants to contribute to nation building and integration by developing and validating Extracurricular instructional Package (EIP) for teaching social studies concept.

\section{PURPOSE OF THE STUDY}

The purpose of this study is to develop extracurricular activities for social studies instruction, specifically to generate extracurricular activities for selected topics in JS 1 social studies, integrate the content with extracurricular activities. Also to compare the learning outcomes in the extracurricular activities group and the conventional teaching group.

\section{Research Questions}

1. To what extent do extracurricular activities help students acquire relevant knowledge skills, attitudes from the following topics in social studies.

i. Meaning and importance of Co-operation

ii. Meaning of Conflict and consequences of non- co-operation

iii. Attitude to work (commitment and dedication to work)

2. What evaluation strategies can best be used to monitor the effectiveness of social studies extracurricular packages?

\section{RESEARCH HYPOTHESES}

$\mathrm{HO}_{1}$. There is no significant difference in the development of co-operative attitude to work by students exposed to social studies extracurricular instructional package (EIP) and their counterparts exposed to the conventional social studies package.

$\mathrm{HO}_{2}$. There is no significant difference in the ability to resolve conflicts by students exposed to social studies extracurricular instructional Package (EIP) when compare with their counterparts exposed to the conventional social studies package. 
H03. There is no significant difference in the commitment/dedication to work by students exposed to social studies extracurricular package compared with their counterparts taught with conventional social studies package.

\section{METHODOLOGY}

\section{Population and Sample}

The population consisted of all the JS1 students in Rivers State, Nigeria using a combination of random and stratified sampling technique, one hundred and sixty students were drawn from four junior secondary school in Ogba-Egbema-Ndoni LGA.

Their baseline knowledge and behaviour were considered, that is: high-ability, average and low ability students were randomly assigned to the experimental and control groups in each of the four sampled school.

\section{INSTRUMENT}

Three types of instruments were used, namely:

1. An Extracurricular Instructional Package (EIP) in the selected topics in JS1 social studies.

2. An instructional package on the same topics using conventional approach

3. An achievement test for each lesson taught with the two approaches. After teaching both the experimental and control groups the stated topics, performance tests given to guide answer the research questions and hypotheses. Questionnaire items and checklists were also used to monitor changes in behaviour of the students. The instruments developed (Extracurricular Instructional Package - EIP) were formatively evaluated to ensure their validity, using the large group approach. Analysis of the data was carried out using t-test, mean and standard deviation.

\section{PROCEDURE}

The experimental group (ET1) was taught the topic "meaning and importance of co-operation" with formatively developed Extracurricular Instructional Package (EIP). The control group (CTI) was taught the same topic (meaning and importance of co-operation) without a developed extracurricular instructional package, using conventional approach.

The meaning of conflict and consequences of non co-operation was taught using Extracurricular Instructional Package (ET2) while the control group (CT2) was taught the same topic with conventional approach. The third topic "Attitude to work' was taught with formatively developed Extracurricular Instructional Package (EIP) to the experimental group (ET3), while the control group (CT 3) was taught the same topic using conventional approach.

\section{RESULT AND DISCUSSION}

\section{Research question 1}

To what extent do extracurricular activities help students acquire relevant knowledge, skill and attitudes from the following topics in social studies?

a. Meaning and importance of co-operation

b. Meaning of conflict and consequences of non co-operation

c. Attitude to work (commitment/dedication).

Table 1: Students Response to EIP (Meaning \& Importance of co-

Operation)

\begin{tabular}{|l|l|l|l|l|l|l|l|}
\hline $\begin{array}{l}\text { Rate the extent to which getting involved in } \\
\text { extracurricular activities can help you to acquire } \\
\text { the following knowledge, skills and attitude }\end{array}$ & A & U & SD & D & & SD \\
\hline Understand the importance of working together & & & & & & & \\
\hline
\end{tabular}




\begin{tabular}{|l|l|l|l|l|l|l|l|l|}
\hline with others & 50 & 26 & 1 & 2 & 2 & 4.46 & 0.42 \\
\hline $\begin{array}{l}\text { Develop interest in working with others } \\
\text { (co-operative skill) }\end{array}$ & & 13 & & & & 4.76 & 0.35 \\
\hline Score higher grades in the class & 65 & & - & 2 & - & 4 \\
\hline
\end{tabular}

Standard reference mean $\mathrm{X}=2.5$

Table 1a above shows that the mean ratings obtained for the various attributes measured (meaning and importance of co-operation), were greater than the standard reference mean of 2.5. This indicates that the students were of the view that the development and participation of extracurricular activities complement in-class teaching which can help them to acquire the following knowledge, skills and attitudes: importance of working together with other (4.46), co-operative skills (4.76). the small values of standard deviations obtained in all the responses indicate that students held similar views.

Table 1(b): Students Responses to EIP (Conflict and Consequences of non co-operation)

\begin{tabular}{|l|l|l|l|l|l|l|l|l|}
\hline $\begin{array}{l}\text { Rate the extent to which getting involved in } \\
\text { extracurricular activities can help you to acquire } \\
\text { the following knowledge, skills and attitude }\end{array}$ & 5 & 4 & 3 & 2 & 1 & Mean & SD \\
\hline Reduce fighting in the school & 63 & 15 & - & 2 & - & 4.74 & 0.36 \\
\hline Develop negative attitude to conflict & 56 & 20 & 1 & 2 & 1 & 4,6 & 0.35 \\
\hline Relate well with my class mate & 53 & 20 & 2 & 1 & - & 4.61 & 0.35 \\
\hline $\begin{array}{l}\text { Become aware of consequences of } \\
\text { non-co-operation }\end{array}$ & 61 & 17 & - & 2 & - & 4.71 & 0.37 \\
\hline
\end{tabular}

Standard Reference 2.5

Three items assessed the level to which getting involved in extracurricular activities help them to reduce fighting in the school, develop negative attitude to conflict, relate well with others and aware of consequences of non-co-operation. The response choices included 1=Disagree, 2 = strongly disagree, $3=$ Undecided, 4 = Agree,

$5=$ Strongly Agree. Data was analyzed. It shows that the mean ratings obtained for the various attributes measured, were greater than the standard references mean of 2.5. This indicates that the students were of the view that participation in extracurricular activities complement in-class teaching, which help them to acquire the following knowledge, skills and attitudes: reduce fighting (4.74), increase social relationship (4.61), negative attitude to conflict (4.6), aware of consequences of non co-operation (4.71). The standard deviations obtained indicate that the students held similar views

Table 1(c): Student Response to EIP (Attitude to work)

\begin{tabular}{|l|l|l|l|l|l|l|l|}
\hline $\begin{array}{l}\text { Rate the extent to which getting involved in } \\
\text { extracurricular activities can help you to acquire } \\
\text { the following knowledge, skills and attitude }\end{array}$ & A & U & SD & D & & \\
\hline Be dedicated to any assigned duty & 40 & 30 & 5 & 3 & 2 & 4.29 & 0.31 \\
\hline Develop self confidence and initiative & 41 & 32 & 3 & 2 & 2 & 4.35 & 0.28 \\
\hline Understand the dangers of being a lousy worker & 62 & 15 & 1 & 2 & 1 & 4.71 & 0.36 \\
\hline
\end{tabular}

Standard reference $\mathrm{X} \quad \overline{\equiv 2.5}$ 


\section{Macrothink Institute ${ }^{\mathrm{TM}}$}

Three items assessed levels of participation in attitude that can be acquired. The items are dedication to assigned duty, self confidence and initiative dangers of lousy worker. The response choice included $5=$ strongly agree, $4=$ Agree, $3=$ undecided, $2=$ strongly disagree, 1 $=$ disagree. The tables above shows that mean ratings obtained for the various attributes measured, were greater than the standard reference mean of 2.5. This indicates that the students were of the view that the development and participation in extra-curricular activities complement in-class teaching which can help to acquire the following knowledge, skills and attitudes: dedication to work (4.29), self confidence and initiative (4.35) and awareness of dangers of being lousy worker (4.71). The standard deviation obtained indicates that the students held similar views.

\section{Research Questions 2}

What evaluation strategies can best be used to monitor the effectiveness of social studies extracurricular package?

Table 2a: Evaluation strategies and their effectiveness to monitor behaviour changes

\begin{tabular}{|l|l|l|l|}
\hline \multicolumn{1}{|c|}{ Evaluation Strategies } & \multicolumn{1}{|c|}{ Behaviour Monitor } & \multicolumn{2}{c|}{ Effectiveness } \\
\hline Checklist & Co-operative skills & High & Low \\
\hline & Punctuality & ' & \\
\hline & Commitment to tasks & ' & \\
\hline & Ability to relate with others & ' & \\
\hline & Efficiency in work & "' & \\
\hline & Ability to resolve conflicts &
\end{tabular}

Respondents rated high

Table 2b: Attitudinal Instrument

\begin{tabular}{|c|l|c|c|}
\hline $\begin{array}{c}\text { Attitudinal Instrument } \\
\text { (Likert Scale) }\end{array}$ & \multicolumn{1}{|c|}{ Develop interest in work with others } & 4.76 & 0.35 \\
\hline & Reduce fighting in the class & 4.74 & 0.36 \\
\hline & Relate well with others in the class & 4.61 & 0.33 \\
\hline & Be dedicated to any duty assigned. & 4.60 & 0.33 \\
\hline & Develop confidence and self initiative & 4.35 & 0.28 \\
\hline & Develop interest in school activities & 4.29 & 0.31 \\
\hline & Develop negative attitude to conflict & 4.6 & 0.33 \\
\hline
\end{tabular}

Table $2 \mathrm{a} \& \mathrm{~b}$ above show that the best evaluation strategies that can be used to monitor social studies effectiveness are the checklist and attitudinal instrument (Likert Scale).

These instruments yielded positive results in monitoring the changes in behavior of the students.

\section{Hypothesis 1}

There is no significant difference in the development of co-operative attitude to work by students exposed to social studies extracurricular instructional package (EIP) and their counterparts exposed to the conventional social studies package.

Table 3: Teaching without extracurricular Instructional package (CT1) Vs Teaching with EIP (ET1)

\begin{tabular}{|l|l|l|l|l|l|l|}
\hline Variables & $\mathrm{N}$ & Mean & SD & t-cal & Critical Value & Df \\
\hline CT1 & 80 & 5.28 & 1.6 & 5.472 & 1.972 & 158 \\
\hline ET1 & 80 & 6.96 & 2.2 & & & \\
\hline
\end{tabular}


Not significant at $=\mathrm{P}=>0.05$

The result from the table 3 above indicates that there is significant difference in the development of co-operative attitude to work by students exposed to social studies extracurricular package and their counterparts exposed to the conventional social studies package in favor of ET1 with higher mean. Hence reject H1 its null form.

\section{Hypothesis 2}

There is no significant difference in the ability to resolve conflicts by students exposed to social studies EIP when compared with their counterparts exposed to conventional social studies package.

Table 4: Teaching without EIP (CT2) vs. Teaching with EIP (ET2).

\begin{tabular}{|l|l|l|l|l|l|l|}
\hline Variables & $\mathrm{N}$ & Mean & SD & t-cal & Critical Value & Df \\
\hline CT2 & 80 & 5.74 & 1.81 & 4.283 & 1.972 & 158 \\
\cline { 1 - 3 } & 80 & 7.01 & 1.93 & & & \\
\hline
\end{tabular}

The result above indicates that the obtained t-cal 4.283 with a degree of freedom of 158 at 0.05 probability level is greater than critical value of 1.972. This shows that there is a significant difference in the ability to resolve conflicts by students exposed to social studies extracurricular package and their counterparts exposed to the conventional social studies package in favour of ET2 Reject null hypothesis.

\section{Hypothesis 3}

There is no significant difference in the commitment/dedication to work by students exposed to social studies EIP compared with their counterparts exposed to the conventional social studies package.

Table 5: Teaching without EIP (CT3) VS Teaching with EIP (ET3).

\begin{tabular}{|l|l|l|l|l|l|l|}
\hline Variables & $\mathrm{N}$ & Mean & SD & t-cal & Critical Value & Df \\
\hline CT2 & 80 & 5.5 & 1.684 & 5.647 & 1.972 & 158 \\
\cline { 1 - 3 } & 80 & 7.125 & 1.925 & & & \\
\hline
\end{tabular}

$* \mathrm{P}=>0.05$

With t-cal 5.647 as against a critical value of 1.972, there is significant difference in the scores of the two groups in favour of the ET3 with higher mean score of 7.125. This indicates that there is significant difference in the dedication/commitment to work by students exposed to social studies extracurricular package and their counterparts exposed to the conventional social studies package.

\section{DISCUSSION OF FINDINGS}

The results of data analyzed showed that the development of extracurricular activities (EIP) in teaching concepts in junior secondary school social studies help the learners to acquire knowledge, skills and attitude. It also enhances learners understanding of such social studies concepts. This finding is in line with those of Rombokas (1995) Silkier and Guardiola (1999) and Stafford (1997) who found that students involved in extracurricular activities receive better grades than those who are not involved in extracurricular activities. In addition, they discovered that activities improve the overall student's intellectual and social development. The investigation also revealed that students exposed to extracurricular activities acquiring such positive learning outcomes, as self-confidence and initiative, cooperative skills, conflict resolution skills and commitment to work. All the attributes measured had mean ratings greater than 2.5 thus indicating that participation in extracurricular activities not only enhance 
academic achievement but build their character. This view is given credence by the works of MCNeal (1995), Rombokas (1995), Camp (1990), Gerber (1996), Marsh (1992), these researchers agreed that extracurricular activities affect the overall well being of the students. Stafford (1997) in his assessment instrument for the effect of extracurricular activities found that: cooperative living (57\%) conflict resolution (50\%) interpersonal relationship (63\%) etc; thus yielding positive effect.

Hypothesis 1 analysis shows that students exposed to extracurricular instructional package ET1 have mean score of 6.96 and standard deviation of 2.2 while the control group CT1 taught with the conventional method had a mean score of 5.28 and SD 1.6 in favour of the experimental group with a higher mean score of 6.96. The result is consistent with other studies that found that students exposed to extracurricular activities learn how to compromise and work in a group, meet and interact with peers that may not be within their close group of friends and develop social skills (Rombokas 1995).

The result of testing hypothesis 2 shows that students exposed to treatment (ET2) have higher mean score of 7.01 and SD 1.93 while the control group CT2 have mean score 5.74, SD 1.81 thus $\mathrm{t}$-cal 4.283 which is greater than $1.972 \mathrm{t}$-ratio with a degree of freedom of 158 at 0.05 level of significance. This indicates that there exists significant difference in the ability to resolve conflicts by students exposed to extracurricular instructional package EIP. The result is consistent with research findings of Stafford (1997) which discovered that extracurricular activities offer maximum opportunity of conflict resolution, interpersonal relationship and communication skills. Extracurricular activities develop team work and exercise their social skills and enable them to develop interest in learning social studies, and deter them from unruly behavior.

\section{RECOMMENDATIONS}

The findings of this study and its consequent implications to education system and nation building make the following recommendations not only necessary but also imperative

1. Education benefits of extracurricular programs should be promoted to school.

2. Restructure teacher's workloads to accommodate their involvement in extracurricular programs by paying staff; more flexible time release from teaching; or restructuring to allow time for activities during school day.

3. More research is required to quantify relationship between extracurricular activities, and educational outcomes.

4. Government through ministry of Education should ensure that schools organize sports, excursion and other extracurricular activities to enrich the student's knowledge, reduce dropout, cultism and crime in the school system.

\section{REFERENCES}

Adeyemi, P.A. (2004) Social Studies for college Students and Teachers Zaria: Library Department, Federal College of Education

Camp, W. (1990) Participation in Students Activities and Achievement; a Covariance Structural Analysis Journal of Educational Research 83.272.278.

Dike, H.I. (2002) Alternative Teaching Approaches for Social Studies with Implications for Science and Social Sciences. Port Harcourt, CAPIIC

Dike, H.I. (1995) Curriculum Improvement and Supervision Port Harcourt CAPIIC publishers 
Federal Republic of Nigeria (2004) National Policy on Education (Revised Edition) Lagos FME Press.

Gerber, S. (1996) Extracurricular Activities and Academic Achievement Journal of Research and Development in Education 30 (1) 42-50

Ibikunle, G.O. (2001) Social Studies as an Integrated subject and its Appropriate Teaching at the Primary School Level of Education in Nigeria. Osiele journal of Educational Studies Abeokuta 3(5-11)

Ituen, S.A.U. (1995) Introduction to Curriculum Studies. Port Harcourt. Abe Publishers.

McNeal, R. (1995) Extracurricular Activities and High School Dropouts. Sociology of Education. 68-81

Marsh, (1992) Extracurricular Activities: Beneficial Extension of the Traditional Curriculum or Subversion of Academic Goals? Journal of Educational Psychology, 84(4), 553-562.

Okorie, J.U (1986) Fundamentals of Teaching Practice. Enugu. Fourth Dimension Publishers.

Rombokas M. (1995) Extracurricular Activities and College: Paper Presented at the South Eastern Counseling Personnel Jeky 11 Islands, G.A Eric Document ED 391-134.

Safford, J.E. (1997) "New Leadership and New Vision http:/www/sfus.Edu/acadplan/wascess 26f.htm.

Silkier, S.R. and Quirt Guardioke J. (1997). The Effect of Extracurricular Activity Participation on the Academic Performance of Male and Female High Students. The School Counselor, 44, 288-293

Ukah, M.O. (2003) THE Challenges of Teacher Education for Sustainable Democracy Implication for the Physical Education and Sports Multidisciplinary Journal of Research Development (1) 13- 21 